TRANSACTIONS OF THE

AMERICAN MATHEMATICAL SOCIETY

Volume 356, Number 5, Page 2137

S 0002-9947(03)03578-5

Article electronically published on December 8, 2003

\title{
ERRATUM TO “THE CENTRAL LIMIT PROBLEM FOR CONVEX BODIES"
}

\author{
MILLA ANTTILA, KEITH BALL, AND IRINI PERISSINAKI
}

The first author's address was printed incorrectly in [1]. Professor Anttila's correct address is:

Department of Mathematics

University of Turku

FIN-20014 Turku

Finland

milant@utu.fi

\section{REFERENCES}

1. Milla Anttila, Keith Ball, and Irini Perissinaki, The central limit problem for convex bodies, Trans. Amer. Math. Soc. 355 (2003), 4723-4735.

Department of Mathematics, University of Turku, Fin-20014 Turku, Finland

E-mail address: milant@utu.fi

Department of Mathematics, University College, University of London, Gower Street, London WC1E 6BT, England

E-mail address: kmb@math.ucl.ac.uk

Department of Mathematics, University of Crete, 710409 Iraklion, Greece

E-mail address: irinip@math.uoc.gr

Received by the editors December 5, 2003.

2000 Mathematics Subject Classification. Primary 52A22; Secondary 60 F05.

(C) 2003 American Mathematical Society 